\title{
VARIASI NILAI HYDROPHYLIC-LIPOPHYLIC BALANCE CAMPURAN SPAN 80- TWEEN 80 DAN INDEX CREAMING INDEX PADA EMULSI COCONUT OIL
}

Devi Maulina

maulinadevi2011@gmail.com, Prodi D-III Farmasi Politeknik Kesehatan Hermina

\begin{abstract}
An emulsion is a dispersion system containing two or more immiscible materials, usually an oil phase and a water phase. Phase separation is generally very rapid if an emulsion is prepared by homogenizing the two pure liquid components, especially if the concentration of the dispersed phase is very high. The way to overcome the phase separation in the emulsion is by adding an emulsifier, a surfactant, to make the emulsion preparation more stable. This research is experimental research conducted at the Pharmacy Laboratory of Politeknik Kesehatan Hermina.. The purpose of this study was to determine the variation in the value of the Hydrophylic-Lipophilic Balance (HLB) mixture of span 80 and tween 80 on the creaming index of coconut oil emulsion. The results showed that the appropriate HLB value for coconut oil emulsion preparations was 14, with a creaming index of $29 \%$ at 96 hours of storage at $25^{\circ} \mathrm{C}$.

Keyword: Emulsion, surfactan, HLB, Cracking index
\end{abstract}

\begin{abstract}
Abstrak
Emulsi merupakan sistem dispersi, mengandung dua atau lebih bahan yang tidak dapat bercampur, biasanya terdiri dari fase minyak dan fase air. Pemisahan fase pada umumnya akan berlangsung sangat cepat jika suatu emulsi dibuat dengan menghomogenkan dua komponen cair murni, terutama jika konsentrasi fase terdispersi sangat tinggi. Cara mengatasi pemisahan fase pada emulsi adalah dengan penambahan zat pengemulsi (emulsifier) salah satunya adalah surfaktan agar sediaan emulsi lebih stabil. Penelitian ini merupakan peneltian eksperimental yang dilakukan di Laboratorium Farmasi Politeknik Kesehatan Hermina. Tujuan penelitian adalah mengetahui variasi nilai HydrophylicLipophylic Balance (HLB) campuran span 80 dan tween 80 terhadap index creaming index pada emulsi coconut oil. Hasil peneltian menunjukan nilai HLB yang sesuai untuk sediaan emulsi coconut oil adalah 14 dengan index creaming $29 \%$ pada 96 jam penyimpanan di suhu $25^{\circ} \mathrm{C}$.
\end{abstract}

Kata kunci: Emulsi, Surfaktan, HLB, creaming index.

\section{PENDAHULUAN}

Emulsi adalah sistem dua fase yang salah satu fasenya terdispersi dalam cairan yang lain dalam bentuk tetesan kecil. Jika minyak yang merupakan fase terdispersi dan larutan air merupakan fase pembawa, sistem ini disebut emulsi minyak dalam air (oil in water-O/W). Sebaliknya, jika air atau larutan air yang merupakan fase terdispersi dan minyak atau bahan seperti minyak merupakan fase pembawa, sistem ini disebut emulsi air dalam minyak (water in oil-W/O). Emulsi memiliki fase terdispersi biasanya dalam ukuran antara 0,1 dan $100 \mu \mathrm{m}$ (Anonim, 2020).

Emulsi dibuat dengan cara mencampur dua fase komponennya dengan penambahan zat pengemulsi (emulsifier). Salah satu emulsifier adalah surfaktan yang dapat menstabilkan emulsi dengan cara menempati antar permukaan fase terdispesi yang berupa tetesan-tetesan dan fase pembawa, dan dengan membuat batas fisik di sekeliling partikel yang akan berkoalesensi. Surfaktan juga mengurangi tegangan antar permukaan antara fase terdispersi dan fase pembawa (Akbari \& Nour, 2018).

Surfaktan memiliki struktur bipolar dengan bagian kepala bersifat hidrofilik dan bagian ekor bersifat lipofilik. Pada emulsi gugus hidrofilik akan berikatan dengan fase air sedangkan gugus 
lipofilik akan berikatan dengan fase minyak. Terdapat tiga jenis surfaktan yang sering digunakan yaitu surfaktan anionik, surfaktan nonionik dan surfaktan kationik. Surfaktan anionik adalah surfaktan dengan muatan negatif, surfaktan kationik adalah surfaktan dengan muatan positif, dan surfaktan nonionik adalah surfaktan yang tidak memiliki muatan (Kurniadie et al., 2017).

Emulsifier memiliki nilai hydrophylic-lipophylic balance (HLB). Jenis emulsi W/O atau O/W ditentukan oleh nilai HLB emulsifier. Umumnya emulsi akan berbantuk tipe O/W bila nilai HLB emulsifier diantara 9-12 dan emulsi tipe bila nilai HLB emulsifier diantara 3-6 (Suardana et al., 2020). Salah satu surfaktan yang paling sering digunakan adalah Tween 80 dan Span 80, keduanya termasuk dalam jenis surfaktan nonionik. Span 80 mempunyai nilai HLB sebesar 4,3 dan tween 80 mempunyai HLB sebesar 15. Kombinasi tween 80 dan span 80 menghasilkan nilai kesetimbangan hidrofilik-lipofilik (HLB) (Suardana et al., 2020).

Nilai HLB kombinasi dari tween 80 dan span 80 yang sesuai untuk pembuatan emulsi coconut oil belum diketahui, sehingga perlu dilakukan pengujian untuk menentukan nilai HLB yang sesuai agar menghasilkan emulsi coconut oil yang stabil.

\section{METODE}

\section{Alat dan Bahan}

Alat dan Bahan: mixer, gelas ukur, beaker glass, penangas air, tabung sedimentasi, minyak kelapa (Coconut oil), aquadest, Tween 80, Span 80.

Metode Penelitian

Penelitian ini merupakan penelitian eksperimental dengan pendekatan deskriptif kualitatif. Pengamatan dilakukan terhadap creaming index emulsi minyak kelapa (coconut oil) dengan kombinasi emulsifier tween 80 dan span 80 dengan nilai HLB 8, 10, 12 dan 14. Creaming index diukur pada $1 \frac{1}{2}$ jam; 1 jam; 24 jam dan 96 jam setelah pembuatan emulsi pada suhu $25^{\circ} \mathrm{C}$.

Pembuatan campuran surfaktan dari Tween 80 dan Span 80 dengan HLB 8 - 14, menggunakan rumus sebagai berikut:

$$
\mathrm{X}=\frac{f 1 x 1+f 2 x 2}{f 1+f 2}
$$

Keterangan:

$\mathrm{X}=$ HLB yang digunakan

$\mathrm{f} 1=$ Berat Surfaktan 1(Tween 80)

f2= Berat surfaktan $2($ Span 80$)$

$\mathrm{x} 1=\mathrm{HLB}$ surfaktan 1 (Tween 80)

x2=HLB surfaktan $2($ Span 80$)$

Pembuatan Emulsi

Ditimbang bahan sesuai dengan formula yang ditentukan. Dicampurkan span 80 dengan coconut oil, Tween 80 dengan air, panaskan masing-masing campuran pada penangas air hingga suhu $70^{\circ} \mathrm{C}$. Gabungkan kedua campuran menggunakan mixer pada kecepatan dan waktu yang sama. 
Pengukuran creaming index

Sampel emulsi coconut oil dengan masing-masing nilai HLB dimasukan kedalam tabung sedimantasi atau gelas ukur, ditutup, dan dibiarkan tegak berdiri selama 96 jam pada suhu penyimpanan $25^{\circ} \mathrm{C}$. Pada umumnya sampel akan memisah menjadi dua fase (creaming). Diamati pembentukan creaming yang terjadi pada $1 \frac{1}{2}$ jam; 1 jam; 24 jam dan 96 jam setelah pembuatan emulsi. Perhitungan creaming index menggunakan rumus sebagai berikut (Hartayanie et al., 2014):

$$
\text { Creaming index }=\frac{h 1}{h 0} \times 100
$$

Keterangan:

$\mathrm{h} 1=$ ketinggian fase krim

h0= ketinggian total emulsi

\section{HASIL DAN PEMBAHASAN}

Tabel 1. Rancangan Formula Emulsi Coconut oil

\begin{tabular}{ccccc}
\hline Bahan & $\begin{array}{c}\text { Formula I } \\
\text { (HLB 8) }\end{array}$ & $\begin{array}{c}\text { Formula II } \\
\text { (HLB 10) }\end{array}$ & $\begin{array}{c}\text { Formula III } \\
\text { (HLB 12) }\end{array}$ & $\begin{array}{c}\text { Formula IV } \\
\text { (HLB 14) }\end{array}$ \\
\hline Coconut oil & 20 & 20 & 20 & 20 \\
Tween 80 & 1,73 & 2,66 & 3,59 & 4,53 \\
Span 80 & 3,27 & 2,34 & 1,41 & 0,47 \\
Aquadest ad & 100 & 100 & 100 & 100 \\
\hline
\end{tabular}

Sumber : data diolah

Tabel 2. Pengamatan creaming index

\begin{tabular}{ccccc}
\hline Formula Emulsi & \multicolumn{4}{c}{ Creaming index(\%) } \\
& $1 / 2$ jam & 1 jam & 24 jam & 96 jam \\
\hline Formula I (HLB 8) & 40 & 56 & 68 & 68 \\
Formula II (HLB 10) & 0 & 38 & 68 & 68 \\
Formula III (HLB 12) & 0 & 10 & 70 & 71 \\
Formula IV (HLB 14) & 0 & 0 & 14 & 29 \\
\hline
\end{tabular}

Sumber : data diolah

Emulsi yang terbentuk pada penelitian ini adalah emulsi tipe oil in water $(\mathrm{O} / \mathrm{W})$ dengan karakteristik warna putih keruh seperti susu, dan tidak dapat ditembus cahaya. Tingkat kestabilan pada emulsi dapat dilihat pada pembentukan creaming yaitu pemisahan emulsi menjadi dua fase. Creaming pada emulsi bersifat reversible artinya kedua fase yang berpisah akan kembali homogen dengan sedikit penggojokan (Sari \& Lestari, 2015). Dapat dilihat pada tabel 2, pada Formula I dengan HLB 8, creaming mulai terbentuk pada setengah jam penyimpanan emulsi dengan index creaming adalah $40 \%$ dan terus meningkat pada penyimpanan 1 jam, 24 jam, dan 96 jam berturutturut adalah 56\%, 68\% dan 68\%. Pada formula II dengan HLB 10, pada setengah jam penyimpanan belum terbentuk creaming, creaming mulai terbentuk setelah 1 jam penyimpanan dengan index creaming adalah $38 \%$ dan meningkat sampai $68 \%$ setelah penyimpanan 96 jam. Pada formula III 
dengan HLB 10, pada setengah jam penyimpanan belum terbentuk creaming, creaming mulai terbentuk setelah 1 jam penyimpanan dengan index creaming adalah $10 \%$ dan meningkat sampai $71 \%$ setelah penyimpanan 96 jam. Sedangkan pada Formula IV tidak terbentuk creaming pada setengah jam dan 1 jam penyimpanan, creaming baru terbentuk setelah 24 jam penyimpanan dengan index creaming yaitu $14 \%$ dan pada penyimpanan 96 jam nilai index creaming $29 \%$.

Berdasarkan pengamatan index creaming pada formula IV cenderung lebih rendah dibanding dengan tiga formula lainnya setelah 96 jam penyimpanan, hal ini menunjukan bahwa pada tipe emulsi coconut oil lebih stabil pada nilai HLB 14. Semakin lama waktu penyimpanan emulsi akan terbentuk creaming yang disebabkan oleh gaya grafitasi dan naiknya tegangan permukaan antara fase yang menyebabkan terjadinya pemisahan antar fase (Sari \& Lestari, 2015).

\section{PENUTUP}

Nilai HLB campuran span 80 dan tween 80 yang sesuai pada emulsi coconut oil adalah HLB 14 dengan index creaming $29 \%$ pada penyimpanan 96 jam.

\section{DAFTAR PUSTAKA}

Akbari, S., \& Nour, A. H. (2018). Emulsion types, stability mechanisms and rheology: A review. International Journal of Innovative Research and Scientific Studies, 1(1), 11-17. https://doi.org/10.53894/ijirss.v1i1.4

Anonim. (2020). Farmakope Indonesia edisi VI. Jakarta: Kementrian Kesehatan Republik Indonesia.

Hartayanie, L., Adriani, M., \& , L. (2014). KARAKTERISTIK EMULSI SANTAN DAN MINYAK KEDELAI YANG DITAMBAH GUM ARAB DAN SUKROSA ESTER [Emulsion Characteristics of Coconut Milk and Soybean Oil Added with Gum Arabic and Sucrose Ester]. Jurnal Teknologi Dan Industri Pangan, 25(2), 152-157. https://doi.org/10.6066/jtip.2014.25.2.152

Kurniadie, D., Sumekar, Y., \& Buana, I. (2017). Pengaruh berbagai jenis surfaktan pada herbisida glufosinat terhadap pengendalian gulma dan hasil tanaman jagung (Zea mays L.) di jatinangor. Kultivasi, 16(2), 2015-2018. https://doi.org/10.24198/kultivasi.v16i2.12211

Sari, D. K., \& Lestari, R. S. D. (2015). Pengaruh waktu dan kecepatan pengadukan terhadap emulsi minyak biji matahari (Helianthus annuus L.) dan air. Jurnal Integrasi Proses, 5(3), 155-159.

Suardana, I. M., Suhendra, L., \& Wrasiati, L. P. (2020). Pengaruh Variasi Nilai Hydrophyliclipophylic balance dan Suhu terhadap Karakteristik Sediaan Krim. Jurnal Rekayasa Dan Manajemen Agroindustri, 8(2), 189. https://doi.org/10.24843/jrma.2020.v08.i02.p04 